outwards at once, they mount up on to the lateral aspect of the penis, the highest and most medially placed trunk reaching a point on the side of that organ varying from 1 to $2.5 \mathrm{~cm}$. from its root. Curving down on the dorso-lateral aspect of the penis they gain its root, pass outwards and slightly upwards into the subcutaneous fat of the abdominal wall about $1 \mathrm{~cm}$. above the pubic spine, run at first parallel to and above Poupart's ligament, and then turning down and crossing it obliquely end, as a rule, in a gland of the superoexternal group which lies just below Poupart's ligament with which its long axis is parallel.

This gland always lies definitely to the outer side of the line of the saphenous vein, and may be within $4 \mathrm{~cm}$. of the anterior superior spine. In their course to this gland the vessels pass sometimes between the superficial epigastric vein and the skin, sometimes underneath it. It often happens that the lower of these trunks curves down from the region of the pubic spine, and ends in one of the supero-internal glands, leaving only a single trunk to take the long course described above.

(b) The outer trunks from the anterior surface, three or four in number, do not run upwards parallel with the raphe, but pass upwards and outwards, and gain the anterior aspect of the spermatic cord. At or a short distance below the level of the pubic spine they curve first outwards and then slightly downwards, and end, after various anastomoses, in glands of the superc-internal and infero-internal group.

Lateral trunks. - These are four or five in number. They run upwards on the lateral aspect of the scrotum and spermatic cord, and curve outwards 1-2 cm. below the pubic spine, to reach the supero-internal and infero-internal glands. Sometimes a trunk runs underneath the saphenous vein, just below its junction with the femoral vein, and ends in an infero-external gland.

Posterior trunks. - On each side of the raphe, and about $0.5 \mathrm{~cm}$. from it, a large collecting trunk runs upwards from the most dependent part of the scrotum towards the perineoscrotal junction. Into this trunk run four or five tributaries, which pass transversely across the posterior surface of the corresponding side of the scrotum from without inwards. The main trunk turns outwards a short distance below the junction of scrotum and perineum, runs at first upwards on the posterior aspect of the spermatic cord, and then turning outwards into the thigh abont $2.5 \mathrm{~cm}$. below the pubic spine ends in a gland of the infero-internal group, lying parallel with the saphenous vein about $2-4 \mathrm{~cm}$. below the saphenofemoral junction.

No collecting trunks accompany the perineal and internal pudic vessels into the pelvis.

In one subject I observed three or four trunks originating in the lower part of the anterior surface of the scrotum, which ran backwards through the lower part of the scrotal septum to end in the main posterior trunk. I have not been able to demonstrate this arrangement in other subjects.

The efferent trunks from the superficial inguinal glands sometimes run to other glands of the same group, and sometimes they join a gland of the deep femoral chain. Most of them, however, converge on two or three large thick-walled trunks which, after piercing the cribriform fascia, run up through the crural canal to the inner side of the femoral vein, and end in glands lying along the inner or pelvic side of the external iliac vessels.

I have never been able to find a trunk that passed by the inguinal glands and primarily entered the intrapelvic glands. There does not appear to be any communication between the superficial lymphatics and those of the tunica vaginalis and testis.

1. In consequence of the very free anastomosis between the superficial lymphatic network of opposite sides, it is obvious that whenever an epithelioma approaches the median raphe the glands of both groins must be removed.

2. In view of the termination of the medial trunks from the anterior surface in the supero-external glands, it is important that, when a growth approaches the anterior raphe, the subcutaneous tissue and glands should be removed to within one inch of the anterior superior spine of the ilium. I have seen recently a case in which a very determined attempt at a radical operation failed because the surgeon had not carried his dissection far enough in an outward direction (see figure). Recurrence took place within nine weeks of the operation in the extreme outer angle of the incision.

3. It is essential to remove the superficial inguinal glands and subcutaneous tissue in which they lie, from practically the whole of Scarpa's triangle, and to carry the upper limit of the dissection well above the inner half of Poupart's ligament. To clear the triangle efficiently the upper three inches $(7.5 \mathrm{~cm}$.) of the internal saphenous vein must be excised and the femoral sheath stripped clean.

In view of Handley's work on permeation of lymphatics and the protective process of peri-Iymphatic fibrosis in cancer of the breast, it is scarcely possible, without further histological investigation, to dogmatise on the necessity of removing all the intervening lymphatic vessels, in addition to primary growth and glands.

It is certain that secondary malignant growths are, in this region, extremely rare in the course of the lymphatic trunks, as compared with growths in the glands; and it may prove that the vulnerability of the vessels is so slight as not to warrant the additional mutilation involved in their complete extirpation.

Many surgeons, however, will consider it their duty to aim at the ideal of complete removal of all possible malignant cells, here as elsewhere, and attention to the above description should provide the necessary anatomical data for an early case. It will rarely be possible after such an operation to bring the skin completely together. As far as the necessarily denuded root of the penis is concerned, it will be possible to cover it in the uncircumcised by incising the prepuce on the dorsum (if there should be a tendency to phimosis), and utilising the additional skin gained by its retraction. Apart from this, skin grafting would be required.

Bibliography.-Bruhns: Archiv fiur Anatomie und Physiologie, 1900. H. T. Butlin: Cancer of the Scrotum in Chimney Sweeps and Others. Brit. Med. Jour., 1892. Handley: Cancer of the Breast. J. K. Jamieson and J. F. Dobson: On the Injection of Lymphatics by Prussian Blue. Journal of Anatomy and Physiology, October, 1910.

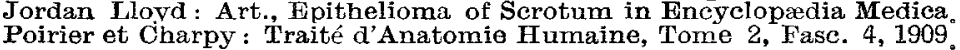
Manchester.

\title{
THE SYSTOLIC BLOOD PRESSURE IN DISEASES OF THE HEART.
}

BY VISHNU T. KORKE, M.R.C.P. EDIN., D.T.M. LIVERP., L.M. \& S. BOMBAY,

LATE ASSISTANT RESIDENT MEDICAL OFFICER, BARNES CONVALESCENT HOSPITAL OF THE MANCHESTER ROYAL INEIRMARY; JOHNSTON GOLONIAI FELLOW IN THE UNTVERSITY OF LIVERPOOL.

THE observations recorded in this paper were made on patients suffering from : (1) simple, uncomplicated valvular lesions of the heart due to acute rheumatic endocarditis; (2) valvular lesions due to other causes; and (3) other heart affections. No systemic complications were observed in cases of valvular lesions due to rheumatic endocarditis. There were no cyanosis, dyspncea, changes in the fundus oculi, febrile temperature, and albuminuria, though traces of albumin were sometimes detected in a few cases. The observations were made on patients of both sezes, of different ages, sent to the Convalescent Hospital from the Manchester Royal Infirmary. They were allowed a mild out-door exercise, and generally they were keeping in good health.

The apparatus used for the observations was a sphygmomanometer, a Martin's modification of Riva-Roci. The systolic blood pressure was recorded by the armlet method during the recumbent posture of the patients. The observations were made daily, under similar circumstances, nearly an hour before dinner (at 1 P.M.), and in cases of doubt they were repeated two to three hours after 8 P.M. A record of pulse-rate and number of respirations was kept during the observations, and sphygmographic tracings of the pulse were often made to note the effect of blood pressure on the pulse. For the convenience of this article only the number of observations and the mean blood pressure are recorded.

The conclusions were arrived at by consulting the following table ${ }^{1}$ :-

$$
\text { Age. }
$$

Children and adolescents

Foung and middle aged (35-45 years) ... ... ... $\}$ over 45 and elderly ... In women 5 to 10 per cent. less than the above figures.

Normal systolic blood

$$
\text { pressure. }
$$

$90 \mathrm{~mm}$. Hg.

1 Oliver : Studies in Blood Pressure, 1908, pp. 81-82. 
Analysis of Observations.

\begin{tabular}{|c|c|c|c|c|c|c|c|}
\hline $\begin{array}{l}\text { Case } \\
\text { No. }\end{array}$ & Sex. & Age. & Cause of the lesion. & Disease. & $\begin{array}{c}\text { Mean blood } \\
\text { pressure } \\
\text { mm. of } \mathrm{Hg} .\end{array}$ & $\begin{array}{l}\text { Remarks about blood } \\
\text { pressure. }\end{array}$ & $\begin{array}{l}\text { Number of } \\
\text { observations. }\end{array}$ \\
\hline 1 & M. & Mid. & Rheumatic endocarditis. & $\begin{array}{l}\text { Aortic incompetence, hypertrophy of left } \\
\text { ventricle, Cheyne-Stokes respirations occa- } \\
\text { sionally. }\end{array}$ & 170 & Supernormal. & 17 \\
\hline 2 & M. & Mid. & ", & Aortic incompetence. & 130 & Little above normal. & 12 \\
\hline 3 & M. & Mid. & ", & ", & 147 & Above normal. & 18 \\
\hline 4 & M. & 19 & $"$ & Aortic and mitral incompetence. & 130 & Well above normal. & 28 \\
\hline 5 & F. & Mid. & ", & $\begin{array}{l}\text { Aortic incompetence, hypertrophy of left } \\
\text { ventricle, signs of arterio-sclerosis. }\end{array}$ & 223 & Supernormal. & 21 \\
\hline 6 & M. & 39 & ", & Mitral incompetence. & 134 & Above normal. & 28 \\
\hline 7 & M. & 16 & $\begin{array}{l}\text { Acute rheumatic } \\
\text { endocarditis. }\end{array}$ & ", & 116 & , & 8 \\
\hline 8 & M. & Mid. & ? & Aortic incompetence, angina pectoris. & 114 & $\begin{array}{c}\text { Below normal during } \\
\text { interparoxysmal } \\
\text { periods. }\end{array}$ & 8 \\
\hline 9 & M. & 20 & Rheumatic endocarditis. & Mitral stenosis. & 116 & Normal. & 25 \\
\hline 10 & M. & 24 & $\because$ & $"$ & 128 & Above normal. & 24 \\
\hline 11 & M. & 15 & , & $"$ & 112 & Little above normal. & 16 \\
\hline 12 & F. & 18 & " & , & 113 & Above normal. & 10 \\
\hline 13 & F. & 20 & $"$ & "2 & 138 & Well above normal. & 29 \\
\hline 14 & F. & 61 & $"$ & ", & 137 & Normal. & 28 \\
\hline 15 & F. & 13 & , & Mitral stenosis and incompetence. & 111 & Above normal. & 9 \\
\hline 16 & F. & 40 & $"$ & Mitral stenosis. & 128 & Little above normal. & 5 \\
\hline 17 & F. & 17 & ", & , & 125 & Well above normal. & 4 \\
\hline 18 & F. & 18 & ", & ", & 118 & Above normal. & 3 \\
\hline 19 & F. & 18 & ", & Mitral incompetence and stenosis. & 108 & Normal. & 21 \\
\hline 20 & $\mathbf{F}$. & 9 & Rheumatism. & Acute endocarditis. & 104 & Little above normal. & 5 \\
\hline 21 & F. & 11 & ", & $\begin{array}{c}\text { Acute endocarditis (patient kept in bed all } \\
\text { the time). }\end{array}$ & 80 & Iittle below normal. & 39 \\
\hline 22 & M. & Mid. & , & Acute endocarditis. & 120 & Normal. & Il \\
\hline 23 & M. & 57 & $?$ & Cardiac muscle failure. & 140 & $"$ & 11 \\
\hline 24 & M. & Mid. & $?$ & , & 160 & Well above normal. & 2 \\
\hline 25 & M. & 23 & $?$ & , & 117 & Normal. & 4 \\
\hline 26 & M. & Mid. & $?$ & , & 125 & ", & 7 \\
\hline 27 & F. & Mid. & $?$ & , & 196 & Supernormal, & 5 \\
\hline 88 & F. & 14 & Rheumatism. & Endocarditis and myocarditis. & 130 & Well above normal. & 6 \\
\hline 29 & M. & Mid. & $?$ & $\begin{array}{c}\text { Aortic incompetence, stenosis, mitral stenosis, } \\
\text { signs of arterio-sclerosis. }\end{array}$ & 181 & Supernormal. & 9 \\
\hline 30 & M. & Mid. & $?$ & Aneurysm of arch of aorta. & 106 & Below normal. & 16 \\
\hline 31 & M. & 25 & - & Tachycardia. & 150 & Supernormal. & 5 \\
\hline 32 & F. & 26 & Goitre. & Mitral regurgitation. & 123 & Normal. & 9 \\
\hline 33 & F. & 20 & Chronic nephritis. & Hypertrophy of left ventricle, arterio-sclerosis. & 180 & Supernormal. & 5 \\
\hline 34 & F. & 16 & $\begin{array}{l}\text { History of diphtheria? } \\
\text { No rheumatism. }\end{array}$ & Mitral stenosis. & 130 & Well above normal. & 6 \\
\hline
\end{tabular}

I.-In valvular lesions of the heart (with or without complications), due to rheumatic endocarditis and other causes, the blood pressure was found to be normal or above normal.

II. - In simple and uncomplicated valvular lesions of the heart, due to acute rheumatic endocarditis, the blood pressure was found always to be normal or above normal. These results agree with those arrived at by Starling. ${ }^{2}$

III. - In aortic incompetence complicated with anginal attacks, the blood pressure was found to be subnormal during the interparoxysmal periods. The low systolic blood pressure is, perhaps, an expression of the failing power of the myocardium.

IV.-Significance of high blood pressure in simple and uncomplicated valvular lesions of the heart due to rheumatic endocarditis. The high blood pressure observed in some of the cases is, I believe, a physiological compensation in those individuals, though it may be mistaken for a pathological state. $A s$ is well understood, the normal blood pressure is maintained by the coördination of the three factors-viz., (1) Rhythmic and forcible contraction of the myocardium; (2) tonic action of the arterial walls; and (3) contraction of the arterioles. In valvular diseases of the heart the defective normal action of the myocardium must be corrected, first, by making a demand on its reserve power; secondly, by supplying a proper amount of blood under the altered circumstances, thereby maintaining a new blood-pressure level. Vaso-constriction is the first effort made to correct the myocardial insufficiency by inciting the ventricles to restore the proper output to its previous amount (Starling) ${ }^{3}$ Consequently the height of blood pressure may vary according to the degree of vaso-constriction, and condition and demand of the myocardium.

For such patients, therefore, who showed no complications and who were comparatively active and comfortable, an average level of arterial blood pressure even above normal was absolutely necessary to ensure the requisite speed of capillary blood flow. ${ }^{4}$ In such cases the high blood pressure was not incompatible with average normal health.

V.-The blood pressure in cardiac muscle failure was normal or well above normal. I believe that the high blood pressure in cardiac muscle failure was due to various pathological causes which produced a change in the myocardium. It was pathological in nature.

VI.-In valvular lesions, complicated with chronic nephritis and arterio-sclerosis, the significance of supernormal blood pressure requires no comment. It is distinctly pathological.

Liverpool.

3 Ibid., p. 848.

4 For the support of these arguments see Janeway, New York Medical Journal, Feb. 2nd, 1907, pp. 193-97; and Oliver, Studies in Blood Sournal, Feb.
Pressure, 1908 .

Univereity College Hospital.-Captain the Honourable Edward Stanley Dawson, R.N., has accepted the appointment of chairman of the Corporation of University College Hospital in succession to the late Earl Cathcart. 